\title{
BMJ Open Association between hyperglycaemic crisis and long-term major adverse cardiovascular events: a nationwide population-based, propensity score-matched, cohort study
}

Li-Hsin Chang, ${ }^{1,2}$ Liang-Yu Lin, ${ }^{2,3}$ Ming-Tsun Tsai, ${ }^{4,5}$ Chorng-Kuang How, ${ }^{2,6}$ Jen-Huai Chiang, ${ }^{7,8,9}$ Vivian Chia-Rong Hsieh, ${ }^{10}$ Sung-Yuan $\mathrm{Hu},{ }^{11,12,13}$ Ming-Shun Hsieh ${ }^{2,6,14,15}$

To cite: Chang L-H, Lin L-Y, Tsai M-T, et al. Association between hyperglycaemic crisis and long-term major adverse cardiovascular events: a nationwide population-based, propensity score-matched, cohort study. BMJ Open 2016;6:e012233. doi:10.1136/bmjopen-2016012233

- Prepublication history for this paper is available online. To view these files please visit the journal online (http://dx.doi.org/10.1136/ bmjopen-2016-012233).

Received 11 April 2016 Revised 19 July 2016 Accepted 29 July 2016

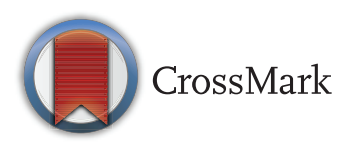

For numbered affiliations see end of article.

Correspondence to Dr Ming-Shun Hsieh; simpleabei@yahoo.com.tw

\section{ABSTRACT}

Objective: Hyperglycaemic crisis was associated with significant intrahospital morbidity and mortality. However, the association between hyperglycaemic crisis and long-term cardiovascular outcomes remained unknown. This study aimed to investigate the association between hyperglycaemic crisis and subsequent long-term major adverse cardiovascular events (MACEs).

Participants and methods: This population-based cohort study was conducted using data from Taiwan's National Health Insurance Research Database for the period of 1996-2012. A total of 2171 diabetic patients with hyperglycaemic crisis fit the inclusion criteria. Propensity score matching was used to match the baseline characteristics of the study cohort to construct a comparison cohort which comprised 8684 diabetic patients without hyperglycaemic crisis. The risk of long-term MACEs was compared between the two cohorts.

Results: Six hundred and seventy-six MACEs occurred in the study cohort and the event rate was higher than that in the comparison cohort (31.1\% vs $24.1 \%$, $p<0.001)$. Patients with hyperglycaemic crisis were associated with a higher risk of long-term MACEs even after adjusting for all baseline characteristics and medications (adjusted $\mathrm{HR}=1.76,95 \% \mathrm{Cl} 1.62$ to 1.92 , $p<0.001$ ). Acute myocardial infarction had the highest adjusted $\mathrm{HR}$ (adjusted $\mathrm{HR}=2.19,95 \% \mathrm{Cl} 1.75$ to 2.75 , $p<0.001$ ) in the four types of MACEs, followed by congestive heart failure (adjusted $\mathrm{HR}=1.97,95 \% \mathrm{Cl}$ 1.70 to $2.28, p<0.001$ ). Younger patients with hyperglycaemic crisis had a higher risk of MACEs than older patients (adjusted HR=2.69 for patients aged 20-39 years vs adjusted $H R=1.58$ for patients aged $>65$ years).

Conclusions: Hyperglycaemic crisis was significantly associated with long-term MACEs, especially in the young population. Further prospective Iongitudinal study should be conducted for validation.

\section{Strengths and limitations of this study}

- This study was conducted by using a nationwide database and a total of 10855 participants were included in the current study.

- This study mainly focused on the long-term cardiovascular outcomes after hyperglycaemic crisis episode rather than intrahospital mortality and was rarely discussed in the literature.

- The propensity score matching was conducted in the current study to avoid selection bias and therefore make the study and comparison cohort patients more comparable.

- The limitation of this study was the lacking of clinical laboratory data and information of patients' lifestyle.

\section{INTRODUCTION}

Globally, diabetes mellitus (DM) affected 371 million people in 2012; this number was expected to rise to 552 million by $2030 .^{12}$ Hyperglycaemic crisis, including diabetic ketoacidosis (DKA) and hyperglycaemic hyperosmolar status (HHS), caused major morbidity and significant mortality in patients with DM. DKA, which is a composite of hyperglycaemia and metabolic acidosis caused by ketonaemia, resulted in a mortality rate of nearly $2 \% .^{3} \mathrm{HSS}$, defined as a serum osmolality of $>320 \mathrm{mOsm} / \mathrm{kg}$, is a form of hyperglycaemic crisis complicated by a deficit of $>10 \mathrm{~L}$ of free water and is responsible for $1 \%$ of the total hospitalisation of patients with diabetes. ${ }^{4} 5$ Compared with DKA, HSS contributed a higher mortality rate ranging from $5 \%$ to $20 \% .^{6}$ Furthermore, the prognosis was substantially worse in the 
presence of coma, hypotension and severe comorbidities. ${ }^{4} 8$ Hyperglycaemic crisis is a particularly critical event in older patients for whom a mortality rate was fivefold higher than that in the general population due to fatal concomitant illness. ${ }^{8}$

Although DKA and HHS are proved to be implicated in the outcomes of diabetes, whether hyperglycaemic crisis is associated with long-term prognosis has not been comprehensively established. A recent national population-based cohort study demonstrated a higher mortality rate in patients with hyperglycaemic crisis in a non-elderly population aged $<65$ years and a twofold increased mortality rate in the 8th year after the hyperglycaemic crisis episode was observed. ${ }^{9}$ Nevertheless, the association between hyperglycaemic crisis and long-term major adverse cardiovascular events (MACEs) was not well established.

The purpose of this study aimed to investigate the association between the hyperglycaemic crisis and subsequent long-term MACEs.

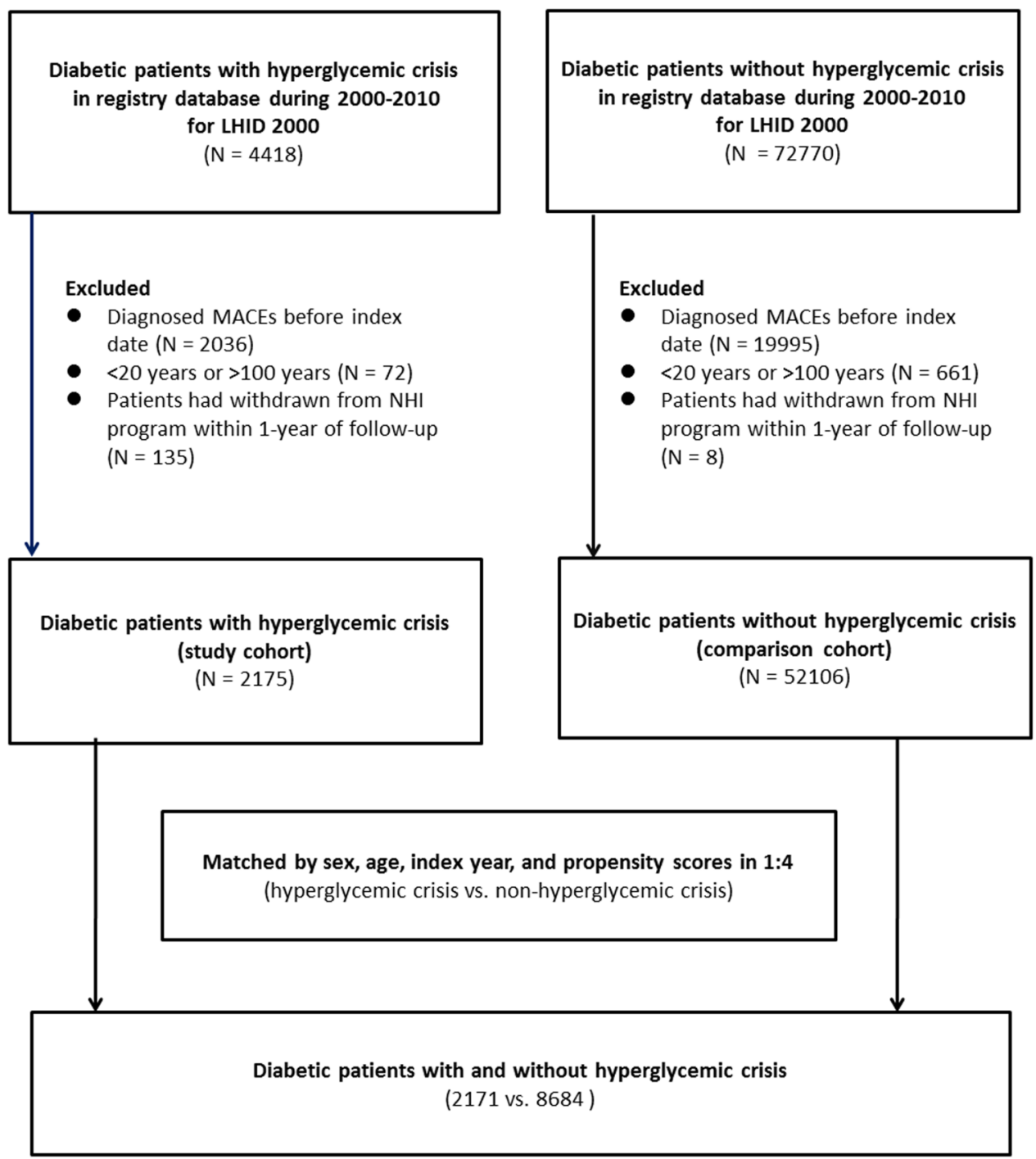

Figure 1 Participants' selection process for the study and comparison cohorts.

\section{METHODS}

\section{Data sources}

We conducted a nationwide population-based cohort study by using data from the National Health Insurance Research Database (NHIRD). The National Health Insurance (NHI) programme in Taiwan was launched on 1 March 1995, by the National Health Insurance Administration (NHIA), providing coverage for $>23.03$ million residents in Taiwan ( $\sim 99.2 \%$ of the population). The NHIA releases identification-encrypted data to the National Health Research Institute (NHRI) to establish the NHIRD. The Longitudinal Health Insurance Database 2000 (LHID2000), used in this study, contains medical information of 1 million beneficiaries randomly sampled from the registry of all beneficiaries in 2000 . Claims data in the LHID2000 were extended from 1 January 1996 to 31 December 2011. Age-related and gender-related distributions in the original claims data and the sampled data do not differ significantly. The diagnosis codes of the International Classification of

abetic patients without hyperglycemic crisis for LHID 2000 $(\mathrm{N}=72770)$ 
Diseases, Ninth Revision, Clinical Modification (ICD-9-CM) are used in the NHIRD.

The NHRI scrambles patient identification and replaces it with surrogate numbers to ensure privacy. Furthermore, data confidentiality is maintained in accordance with NHIA and NHRI data regulations. Since the NHIRD contains de-identified secondary data for research, our study was exempted from the requirement to obtain informed consent from participants. This study was approved by the Institutional Review Board of China Medical University (CMUH104-REC2-115).

\section{Study population and outcomes}

Patients with diabetes were identified by the diagnostic code, ICD-9-CM 250. The study and comparison cohort patients had DM before being included for matching and further analysis. Hyperglycaemic crisis was defined by ICD-9-CM 250.2x for HHS and ICD-9-CM 250.1x for DKA. The first episode of hyperglycaemic crisis was defined as the index time, and the index year was defined as the calendar year of the index time. The MACEs were defined as compositions of acute myocardial infarction (AMI; ICD-9-CM 410), congestive heart failure (CHF; ICD-9-CM 428.0 to 428.10 ), ischaemic or haemorrhagic stroke (ICD-9-CM 430 to 437) and malignant dysrhythmia (ICD-9-CM 246.0, 426.12 to 426.13, 426.51, 426.52, 426.54, 427.1, 427.4, 427.5).$^{10-13}$ Diabetic patients with history of previous MACEs before inclusion, patients aged $<20$ or $>100$ years and individuals who withdrew from the NHI programme within 1 year of follow-up were excluded from the study. For each of the diabetic patients with hyperglycaemic crisis (study

Table 1 Baseline characteristics in patients with and without hyperglycaemic crisis

\begin{tabular}{|c|c|c|c|c|c|}
\hline \multirow{3}{*}{ Variables } & \multicolumn{4}{|c|}{ Hyperglycaemic crisis } & \multirow{3}{*}{ p Value } \\
\hline & \multirow{2}{*}{\multicolumn{2}{|c|}{$\begin{array}{l}\text { No } \\
(\mathrm{N}=8684)\end{array}$}} & \multirow{2}{*}{\multicolumn{2}{|c|}{$\begin{array}{l}\text { Yes } \\
(\mathrm{N}=2171)\end{array}$}} & \\
\hline & & & & & \\
\hline \multicolumn{6}{|l|}{ Sex } \\
\hline Female & 3874 & 44.61 & 981 & 45.19 & \multirow[t]{2}{*}{0.6294} \\
\hline Male & 4810 & 55.39 & 1190 & 54.81 & \\
\hline 18-39 & 1033 & 11.90 & 273 & 12.57 & \multirow[t]{3}{*}{0.1318} \\
\hline $40-64$ & 4709 & 54.23 & 1125 & 51.82 & \\
\hline$\geq 65$ & 2942 & 33.88 & 773 & 35.61 & \\
\hline Mean (SD) & \multicolumn{2}{|c|}{$57.85(14.39)$} & \multicolumn{2}{|c|}{$58.18(15.04)$} & 0.3593 \\
\hline \multicolumn{6}{|c|}{ Insurance premium (New Taiwan dollars) } \\
\hline$<20000$ & 6831 & 78.66 & 1708 & 78.67 & 0.5812 \\
\hline 1 (highest) & 2212 & 25.47 & 524 & 24.14 & \multirow[t]{5}{*}{0.7311} \\
\hline 2 & 2472 & 28.47 & 634 & 29.2 & \\
\hline 3 & 1484 & 17.09 & 383 & 17.64 & \\
\hline 4 & 1348 & 15.52 & 332 & 15.29 & \\
\hline 5 (lowest) & 1168 & 13.45 & 298 & 13.73 & \\
\hline \multicolumn{6}{|l|}{ Types of occupation } \\
\hline Government, school employees & 721 & 8.3 & 172 & 7.92 & \multirow[t]{5}{*}{0.3865} \\
\hline Private enterprise employees & 2677 & 30.83 & 685 & 31.55 & \\
\hline Occupational members & 1688 & 19.44 & 427 & 19.67 & \\
\hline Farmers or fishermen & 2062 & 23.74 & 478 & 22.02 & \\
\hline Low-income households & 1536 & 17.69 & 409 & 18.84 & \\
\hline \multicolumn{6}{|l|}{ Medication } \\
\hline Anticoagulants & 95 & 1.09 & 24 & 1.11 & 0.9632 \\
\hline Antiplatelet drugs & 3203 & 36.88 & 817 & 37.63 & 0.5183 \\
\hline Statins & 617 & 7.11 & 168 & 7.74 & 0.3082 \\
\hline
\end{tabular}


cohort), four diabetic patients without hyperglycaemic crisis were selected from the database as the comparison cohort, after matching for age, sex, index year and propensity scores. The propensity scores used in this study were composed of comorbidities and medications, calculated via logistic regression. The medications in the propensity scores included antiplatelet drugs, anticoagulants and statins. Propensity score matching could reduce the selection bias as it is capable of bundling many confounding covariates that are presented in an observational study.

\section{Potential confounders}

We systematically identified the potential confounders for MACEs by referring to the ICD-9-CM codes in the claims data. The identified confounding factors were age, gender, insurance premium, level of urbanisation, occupation, comorbidities and medications. The comorbidities associated with MACEs were hypertension (ICD-9-CM 401-405), hyperlipidaemia (ICD-9-CM 272), chronic kidney disease (CKD; ICD-9-CM 581-588, 403404, 285.21, 250.4), chronic obstructive pulmonary disease (COPD; ICD-9-CM-490-492,494,496), peripheral arterial occlusive disease (PAOD; ICD-9-CM 440-444) and gout (ICD-9-CM 274). The prescriptions of anticoagulants, antiplatelet drugs and statins were also taken into adjustment.

\section{Statistical analyses}

Differences in demographic characteristics and comorbidities between the study (diabetic patients with hyperglycaemic crisis) and comparison (diabetic patients without hyperglycaemic crisis) cohort patients were examined using the $\chi^{2}$ tests for non-continuous variables and two-sample Student's t-tests for continuous variables. HRs with $95 \%$ CIs were calculated for each variable using Cox proportional hazards regression. Difference in the incidence of MACEs between the study and comparison cohort patients was estimated using Kaplan-Meier analysis with log-rank test. Statistical analyses were performed using the SAS V.9.4 statistical package (SAS Institute, Cary, North Carolina, USA), and the level of significance was set at 0.05 .

\section{RESULTS}

\section{Cases identification and baseline characteristics}

From the 1 million beneficiaries in the database, 4418 diabetic patients with hyperglycaemic crisis during 2000-2010 were identified initially. Among these patients, 2036 patients who had MACEs before the index date were excluded. Seventy-two patients who aged $<20$ or $>100$ years were excluded. Also, 135 patients who had withdrawn from the NHI programme within 1 year of follow-up were excluded (included 132 patients who were expired during the same hospitalisation with the first episode of hyperglycaemic crisis). Finally, a total of 2175 diabetic patients with hyperglycaemic crisis were selected for further analysis. The outcomes were measured after discharge from the hospitalisation for first episode of hyperglycaemic crisis until the end of 2011, that is, the MACEs during the hospitalisation with the first episode of hyperglycaemic crisis were not included as outcomes.

For comparison, a total of 72770 diabetic patients without hyperglycaemic crisis in the database during 2000-2010 were identified. After using the same exclusion criteria for the study cohort, a total of 52106 diabetic patients were selected for further analysis. We further matched the study and comparison cohort patients with age, sex, index year and propensity scores in a 1:4 ratio, and finally, a total of 2171 patients with hyperglycaemic crisis and 8684 patients without hyperglycaemic crisis were included as the study and comparison cohort patients, respectively. The selection process is shown in figure 1 . There were no significant differences in all baseline characteristics, including age, gender, insurance premium, urbanisation, comorbidities or medications (included antiplatelet drugs, anticoagulants and statins).

The median duration of follow-up period was 3.09 years for diabetic patients with hyperglycaemic crisis (study cohort) and 4.70 years for those without hyperglycaemic crisis (comparison cohort) (table 1). In the LHID2000, there were 149427 patients with diabetes included in the database and 7003 patients with diabetes had suffered from at least one episode of hyperglycaemic crisis. The incidence of hyperglycaemic crisis in our whole study population is $4.69 \%$.

\section{Major adverse cardiovascular events}

Two thousand seven hundred and seventy-six MACEs were identified during the study period, including 676 events that occurred in patients with hyperglycaemic

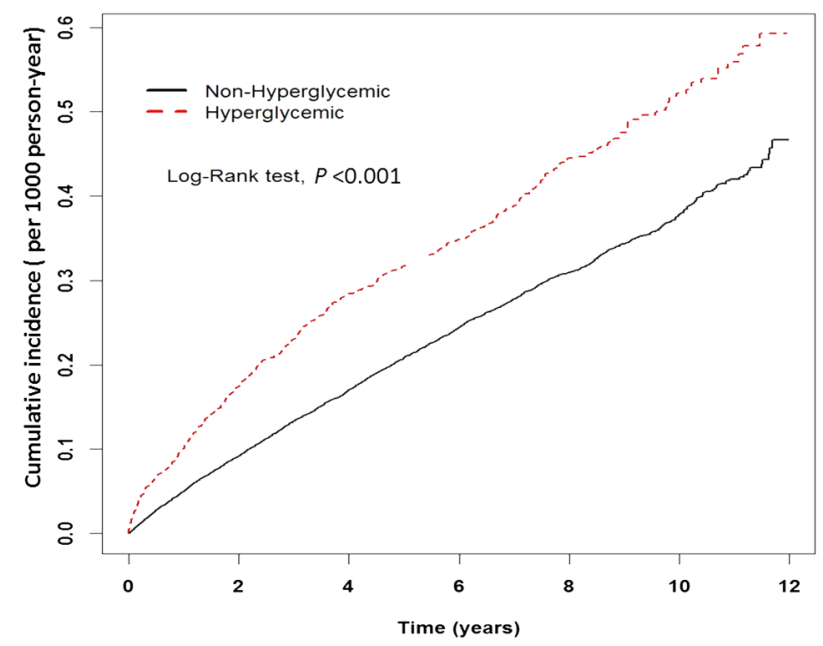

Figure 2 The cumulative incidence of major adverse cardiovascular events between the study and comparison cohorts. LHID, Longitudinal Health Insurance Database; MACEs, major adverse cardiovascular events; NHI, National Health Insurance. 
crisis and 2100 events that occurred in patients without hyperglycaemic crisis. The study cohort patients had a higher cumulative incidence rate of MACEs than the comparison cohort patients during the follow-up period $(31.1 \%$ vs $24.1 \%, \mathrm{p}<0.001$ by log-rank test; figure 2$)$. In the univariate analysis, there was a 1.65 -fold higher incidence of MACEs in the study cohort compared with the comparison cohort (crude HR=1.65, 95\% CI 1.51 to 1.80 , $\mathrm{p}<0.001)$. In addition to episodes of hyperglycaemic crisis, age, insurance premium, urbanisation, occupation and medications (including antiplatelet drugs, anticoagulants and statins) were associated with outcomes as well as all comorbidities, including hypertension, hyperlipidaemia, CKD, COPD, gout and PAOD. After adjusting for age, sex, insurance premium, urbanisation, occupation, all comorbidities and medications in the multivariate Cox proportional hazards regression analysis, the association between hyperglycaemic crisis and MACEs still remained significant (adjusted $\mathrm{HR}=1.76$, 95\% CI 1.62 to $1.92, \mathrm{p}<0.001$; table 2). Among the four types of MACEs, AMI had the highest adjusted HR in patients with hyperglycaemic crisis compared with

Table 2 The association between variables and MACEs measured by the Cox regression model

\begin{tabular}{|c|c|c|c|c|c|}
\hline \multirow[b]{2}{*}{ Characteristics } & \multirow{2}{*}{$\begin{array}{l}\text { Number } \\
\text { of MACEs } \\
(n=2776)\end{array}$} & \multicolumn{2}{|l|}{ Crude } & \multicolumn{2}{|l|}{ Adjusted $†$} \\
\hline & & HR (95\% Cl) & p Value & HR (95\% Cl) & p Value \\
\hline \multicolumn{6}{|l|}{ Hyperglycaemic crisis } \\
\hline No & 2100 & 1.00 (reference) & & 1.00 (reference) & \\
\hline Yes & 676 & $1.65(1.51$ to 1.80$)$ & $<0.0001^{\star \star \star}$ & 1.76 (1.62 to 1.92$)$ & $<0.0001^{* * *}$ \\
\hline \multicolumn{6}{|l|}{ Sex } \\
\hline Female & 1241 & 1.00 (reference) & & 1.00 (reference) & \\
\hline Male & 1535 & $1.06(0.98$ to 1.14$)$ & 0.1601 & $1.10(1.02$ to 1.19$)$ & $0.0132^{*}$ \\
\hline \multicolumn{6}{|l|}{ Age } \\
\hline 18-39 & 78 & 1.00 (reference) & & 1.00 (reference) & \\
\hline $40-64$ & 1205 & 3.79 (3.01 to 4.76$)$ & $<0.0001^{\star * \star}$ & 3.22 (2.55 to 4.07$)$ & $<0.0001^{\star \star *}$ \\
\hline$\geq 65$ & 1493 & 9.81 (7.81 to 12.33$)$ & $<0.0001^{\star * *}$ & $6.92(5.45$ to 8.78$)$ & $<0.0001^{* * *}$ \\
\hline \multicolumn{6}{|c|}{ Insurance premium (New Taiwan dollars) } \\
\hline$<20000$ & 2318 & 1.00 (reference) & & 1.00 (reference) & \\
\hline $20000-39999$ & 319 & 0.69 (0.61 to 0.78$)$ & $<0.0001^{\star * \star}$ & 0.90 (0.8 to 1.02$)$ & 0.0985 \\
\hline $40000-59999$ & 117 & $0.64(0.53$ to 0.78$)$ & $<0.0001^{\star * *}$ & 0.80 (0.66 to 0.97$)$ & $0.0213^{*}$ \\
\hline$\geq 60000$ & 22 & 0.65 (0.43 to 0.99$)$ & $0.0455^{\star}$ & $0.77(0.5$ to 1.18$)$ & 0.2309 \\
\hline \multicolumn{6}{|l|}{ Urbanisation level } \\
\hline 1 (highest) & 662 & 1.00 (reference) & & 1.00 (reference) & \\
\hline 2 & 777 & $1.04(0.94$ to 1.15$)$ & 0.4847 & 1.05 (0.94 to 1.17$)$ & 0.4163 \\
\hline 3 & 438 & 1.02 (0.9 to 1.15$)$ & 0.7954 & $1.00(0.87$ to 1.14$)$ & 0.9494 \\
\hline 4 & 448 & $1.16(1.03$ to 1.31$)$ & $0.0145^{\star}$ & 1.06 (0.91 to 1.22$)$ & 0.4755 \\
\hline 5 (lowest) & 451 & $1.43(1.27$ to 1.61$)$ & $<0.0001^{\star \star \star}$ & $1.22(1.04$ to 1.43$)$ & $0.0157^{*}$ \\
\hline \multicolumn{6}{|l|}{ Types of occupation } \\
\hline Government, school employees & 211 & 1.00 (reference) & & 1.00 (reference) & \\
\hline Private enterprise employees & 711 & $0.91(0.78$ to 1.06$)$ & 0.2421 & $1.13(0.97$ to 1.33$)$ & 0.1144 \\
\hline Occupational member & 459 & $0.90(0.76$ to 1.05$)$ & 0.1864 & 1.04 (0.88 to 1.23$)$ & 0.6411 \\
\hline Farmers, fishermen & 818 & $1.47(1.26$ to 1.71$)$ & $<0.0001^{\star \star \star}$ & $1.10(0.93$ to 1.3$)$ & 0.2775 \\
\hline Low-income households & 577 & 1.36 (1.16 to 1.60$)$ & $<0.0001^{\star \star \star}$ & $1.12(0.95$ to 1.32$)$ & 0.1685 \\
\hline \multicolumn{6}{|l|}{ Comorbidity } \\
\hline Hypertension & 2196 & 2.46 (2.24 to 2.69$)$ & $<0.0001^{\star \star \star}$ & $1.52(1.38$ to 1.68$)$ & $<0.0001^{* * *}$ \\
\hline Hyperlipidaemia & 1696 & 1.29 (1.19 to 1.39$)$ & $<0.0001^{\star \star \star}$ & 1.03 (0.95 to 1.12$)$ & 0.4638 \\
\hline CKD & 752 & 1.52 (1.39 to 1.65$)$ & $<0.0001^{\star \star \star}$ & $1.24(1.13$ to 1.35$)$ & $<0.0001^{* * *}$ \\
\hline COPD & 954 & 1.46 (1.35 to 1.58$)$ & $<0.0001^{\star \star *}$ & 1.08 (0.99 to 1.17$)$ & 0.0782 \\
\hline Gout & 728 & 1.21 (1.11 to 1.32$)$ & $<0.0001^{\star \star \star}$ & 0.97 (0.89 to 1.06$)$ & 0.5553 \\
\hline PAOD & 370 & $1.66(1.49$ to 1.86$)$ & $<0.0001^{\star \star \star}$ & 1.16 (1.04 to 1.3$)$ & $0.0092^{\star *}$ \\
\hline \multicolumn{6}{|l|}{ Medication } \\
\hline Anticoagulants & 47 & 2.15 (1.61 to 2.86$)$ & $<0.0001^{\star * \star}$ & 1.46 (1.09 to 1.95$)$ & $0.0115^{\star}$ \\
\hline Antiplatelet drugs & 1223 & $1.61(1.5$ to 1.74$)$ & $<0.0001^{\star * \star}$ & 1.19 (1.1 to 1.29$)$ & $<0.0001^{* * *}$ \\
\hline Statins & 209 & 1.35 (1.17 to 1.55$)$ & $<0.0001^{\star * \star}$ & $1.03(0.89$ to 1.2$)$ & 0.6738 \\
\hline
\end{tabular}

${ }^{*} \mathrm{p}<0.05 ;{ }^{* *} \mathrm{p}<0.01 ;{ }^{* * *} \mathrm{p}<0.001$.

†Adjusted for age, sex, socioeconomic status, comorbidity and medication.

CKD, chronic kidney disease; COPD, chronic obstructive pulmonary disease; MACE, major adverse cardiovascular events; PAOD, peripheral arterial occlusive disease. 


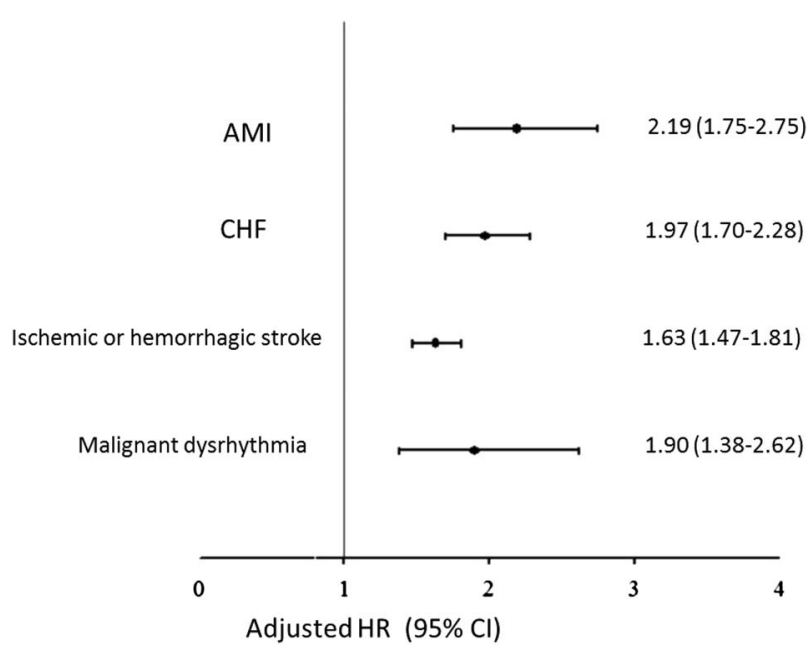

Figure 3 HRs of different MACEs. AMI, acute myocardial infarction; CHF, congestive heart failure; MACEs, major adverse cardiovascular events.

patients without hyperglycaemic crisis (adjusted $\mathrm{HR}=2.19$, 95\% CI 1.75 to 2.75, p<0.001), followed by CHF (adjusted $\mathrm{HR}=1.97$, 95\% CI 1.70 to $2.28, \mathrm{p}<0.001$ ), malignant dysrhythmia (adjusted $\mathrm{HR}=1.90,95 \%$ CI 1.38 to 2.62, $\mathrm{p}<0.001$ ) and ischaemic or haemorrhagic stroke (adjusted $\mathrm{HR}=1.63,95 \%$ CI 1.47 to 1.81 , $\mathrm{p}<0.001$; figure 3 ).

Stratification by age and sex in both cohorts was conducted and the associations between hyperglycaemic crisis and MACEs in every stratum of age and sex were analysed. Hyperglycaemic crisis in male and female patients was associated with increased HR of MACEs and a higher adjusted HR in female patients was found after adjusting for all covariates in the multivariate Cox proportional hazards regression analysis (adjusted $\mathrm{HR}=1.89$, $95 \%$ CI 1.67 to $2.15, \mathrm{p}<0.001$ for women; adjusted $\mathrm{HR}=1.66,95 \%$ CI 1.47 to $1.88, \mathrm{p}<0.001$ for men; table 3 ). Hyperglycaemic crisis was associated with an increased risk of MACEs in all age strata, but the HR decreased as age increased. Younger individuals with hyperglycaemic crisis had a higher risk of MACEs than their older counterparts even after adjusting for all baseline covariates (adjusted HR=2.60, 95\% CI 1.63 to $4.16, \mathrm{p}<0.001$ for aged 20-39 years; adjusted HR=1.96, 95\% CI 1.72 to 2.22, $\mathrm{p}<0.001$ for aged $40-64$ years; adjusted $\mathrm{HR}=1.57,95 \%$ CI 1.39 to $1.78, p<0.001$ for aged $\geq 65$ years; table 3 ).

\section{DISCUSSION}

This study demonstrated that hyperglycaemic crisis was associated with an increased risk of subsequent MACEs. Krinsley demonstrated that hyperglycaemia was a positive predictor of in-hospital mortality in critically ill patients. The patients with serum glucose over $300 \mathrm{mg} / \mathrm{dL}$ exhibited the highest mortality rate $(42.5 \%) .{ }^{14}$ Furthermore, hyperglycaemia was associated with worse outcomes in patients who were hospitalised in the general ward irrespective of history of diabetes. ${ }^{15}$ Even though the association between hyperglycaemia and in-hospital outcomes is a widely accepted concept, the relationship between hyperglycaemic crisis and subsequent outcomes after discharge is not well established. In the current study, we aimed to evaluate the association between hyperglycaemic crisis and subsequent MACEs after discharge for hyperglycaemic crisis.

The worse subsequent outcomes in patients with hyperglycaemic crisis might be induced by inflammation. Stentz et $a l^{16}$ reported twofold to fourfold higher levels of inflammatory markers, including cytokine (interleukin-1 $\beta, 6$ and 8; tumour necrosis factor- $\alpha$ ), cardiovascular risk markers $(\mathrm{C}$ reactive protein and homocysteine), reactive oxygen species, cortisol and growth hormone in patients with hyperglycaemic crisis. Also, the phenomenon of hyperglycaemic memory may provide another explanation to the association between hyperglycaemic crisis and MACEs. The detrimental

Table 3 Incidence rate of MACEs for patients with hyperglycaemic crisis, stratified by age and sex

\begin{tabular}{|c|c|c|c|c|c|c|c|c|}
\hline \multirow[b]{4}{*}{ Variables } & \multicolumn{6}{|c|}{ Hyperglycaemic crisis } & \multirow{4}{*}{$\begin{array}{l}\text { Crude HR } \\
(95 \% \mathrm{Cl})\end{array}$} & \multirow{4}{*}{$\begin{array}{l}\text { Adjusted HR } \\
(95 \% \mathrm{Cl})\end{array}$} \\
\hline & \multirow{2}{*}{\multicolumn{3}{|c|}{$\begin{array}{l}\text { No } \\
(\mathrm{N}=8684)\end{array}$}} & \multirow{2}{*}{\multicolumn{3}{|c|}{$\frac{\text { Yes }}{(\mathrm{N}=2171)}$}} & & \\
\hline & & & & & & & & \\
\hline & Event & Person-years & IR† & Event & Person-years & IR† & & \\
\hline Total & 2100 & 44228 & 47.48 & 676 & 8565 & 78.93 & $1.65(1.51 \text { to } 1.80)^{\star \star \star}$ & $1.76(1.62 \text { to } 1.92)^{\star \star \star}$ \\
\hline \multicolumn{9}{|c|}{ (1) } \\
\hline Female & 908 & 20336 & 44.65 & 333 & 3992 & 83.41 & $1.85(1.63 \text { to } 2.1)^{\star \star \star}$ & $1.89(1.67 \text { to } 2.15)^{\star \star \star}$ \\
\hline Male & 1192 & 23892 & 49.89 & 343 & 4573 & 75.01 & $1.49(1.32 \text { to } 1.68)^{\star \star \star}$ & $1.66(1.47 \text { to } 1.88)^{\star \star \star}$ \\
\hline \multicolumn{9}{|l|}{ Age§ } \\
\hline 20-39 & 47 & 6042 & 7.78 & 31 & 1472 & 21.06 & $2.69(1.71 \text { to } 4.24)^{\star \star \star}$ & $2.60(1.63 \text { to } 4.16)^{\star \star \star}$ \\
\hline $40-64$ & 884 & 25691 & 34.41 & 321 & 4938 & 65.00 & $1.89(1.66 \text { to } 2.15)^{\star \star \star}$ & $1.96(1.72 \text { to } 2.22)^{\star \star *}$ \\
\hline$\geq 65$ & 1169 & 12495 & 93.56 & 324 & 2155 & 150.37 & $1.58(1.40 \text { to } 1.79)^{\star \star \star}$ & $1.57(1.39 \text { to } 1.78)^{\star \star \star}$ \\
\hline \multicolumn{9}{|c|}{$\begin{array}{l}\text { Adjusted HR: adjusted for hyperglycaemic crisis, age, sex, socioeconomic status, comorbidity and medications. } \\
\text { †Per } 1000 \text { person-years. } \\
\text { †Adjusted for all covariates in the full model except sex. } \\
\S \text { Adjusted for all covariates in the full model except age. } \\
\text { IR, incidence rates; MACE, major adverse cardiovascular events. }\end{array}$} \\
\hline
\end{tabular}


effects of hyperglycaemia may not vanish immediately after correction of hyperglycaemia. ${ }^{17}{ }^{18}$ Similar phenomena were observed in the other extreme of glycaemic emergency, that is, hypoglycaemia. Razavi Nematollahi et $a l^{19}$ demonstrated elevation of pro-inflammatory cytokine and reactive oxygen species through the activation of stress hormones, including cortisol, epinephrine and norepinephrine in participants with hypoglycaemia. Since hypoglycaemia has been demonstrated to exert a deleterious effect on long-term survival and has been shown to contribute to increase risks of microvascular and macrovascular complications of diabetes, it is reasonable to infer that hyperglycaemic crisis shares similar molecular mechanisms and thereafter causes subsequent worse MACE outcomes. ${ }^{20} 21$

The risk of MACEs was reported to be attenuated by increased age in populations with diabetes. Among 435369 patients with diabetes registered in the Swedish National Diabetes Register on or after 1 January 1998, the all-cause mortality or cardiovascular mortality rate was about 2.59-fold to 2.8-fold higher in patients with diabetes aged below 55 years compared with control groups, but was only 1.19-fold to 1.02-fold higher in patients aged over 75 years. ${ }^{22}$ The trends of mortality in patients with and without diabetes in Ontario, Canada and the UK between 1996 and 2009 also demonstrated an increased mortality rate of twofold to threefold among patients aged 45-64 years and an increased mortality rate of fourfold to fivefold among patients aged 20-44 years. ${ }^{23}$ Even though the mortality rate was attenuated among older people, Tancredi et $a t^{22}$ emphasised that the impact of comorbidities should be considered when interpreting the results of epidemiological studies. In our study, age, sex and major comorbidities were matched between the study and comparison cohorts by propensity scores; however, the worse MACE outcomes in younger patients were still observed, which were consistent with previous population-based studies.

Since the true mechanism for younger diabetes with worse cardiovascular prognosis was still inconclusive, we still cannot make a clear conclusion here. Further investigation should be conducted to clarify this phenomenon. Tancredi et al proposed that some factors other than traditional ones might be involved in the outcomes of young diabetes; therefore, cessation of smoking, increase of daily activity and development of new medication for preventing cardiovascular events should be promoted in young diabetes. ${ }^{20}$ Our study result may serve as a reminder that more intensive multifactorial approach should be considered in patients with diabetes diagnosed at a young age, and primary prevention of hyperglycaemic crisis in this population is thus strongly warranted.

Worse outcomes were also found in patients with lower insurance premium and lower urbanisation level and we infer that an association between socioeconomic status and outcomes exists. According to the 2013 Global Burden of Disease report, the residents in the
USA, which was considered a high-income country, had longer life expectancy for both genders compared with other global populations. A relationship between socioeconomic status and premature mortality was also noted in an analysis conducted by the Australian Diabetes Obesity and Lifestyle; the premature mortality rate was 1.48-fold higher in the most disadvantaged area compared with the least disadvantaged area, and multiple modifiable risk factors, such as smoking, diet quality and physical activity, may play a role in this association. ${ }^{24}$ An epidemiological study conducted in Brazil also demonstrated that lower income groups had the greatest risk of cardiovascular disease, particular in young age groups. ${ }^{25}$ Since the socioeconomic status of diabetes was associated with subsequent outcomes, public health policy should be designed to meet the healthcare needs of diabetic patients with lower socioeconomic status to promote the primary prevention of cardiovascular diseases.

There were some limitations in this study. First, the NHIRD did not contain data on laboratory tests, so it was impossible to evaluate the effects of various parameters known to be associated with MACEs, such as lipid profiles. However, we matched the study and comparison cohort patients in the comorbidities and medications, which were directly correlated with these risk factors by using propensity scores. Second, some important variables that were associated with the risk of diabetes, including body mass index, history of smoking and blood pressure, were not included in this analysis. Nevertheless, we used the diagnoses of COPD and hypertension to substitute these unavailable information and made adequate adjustment in the analyses accordingly. Third, the potential risk of ICD-9 overcoding or overtreatment could not be totally excluded. Fourth, because of retrospective study design, the direct causality between hyperglycaemic crisis and long-term MACEs could not be well clarified. Further prospective study should be conducted for validating the results of this study.

\section{Conclusion}

From this nationwide population-based cohort study, we observed an association between hyperglycaemic crisis and subsequent MACEs, especially in the young population. Further prospective longitudinal study should be conducted.

\section{Author affiliations}

${ }^{1}$ Division of Endocrinology and Metabolism, Department of Internal Medicine, Taipei Veterans General Hospital, Taoyuan Branch, Taoyuan, Taiwan

${ }^{2}$ School of Medicine, National Yang-Ming University, Taipei, Taiwan

${ }^{3}$ Division of Endocrinology and Metabolism, Department of Internal Medicine, Taipei Veterans General Hospital, Taipei, Taiwan

${ }^{4}$ Division of Nephrology, Department of Internal Medicine, Taipei Veterans General Hospital, Taoyuan Branch, Taoyuan, Taiwan

${ }^{5}$ Institute of Clinical Medicine, National Yang-Ming University, Taipei, Taiwan

${ }^{6}$ Department of Emergency Medicine, Taipei Veterans General Hospital, Taipei,

Taiwan

${ }^{7}$ Graduate Institute of Integrated Medicine, College of Chinese Medicine,

Research Center for Chinese Medicine \& Acupuncture, China Medical

University, Taichung, Taiwan 
${ }^{8}$ College of Medicine, China Medical University, Taichung, Taiwan

${ }^{9}$ Management Office for Health Data, China Medical University, Taichung, Taiwan

${ }^{10}$ Department of Health Services Administration, China Medical University, Taichung, Taiwan

${ }^{11}$ Department of Emergency Medicine, Taichung Veterans General Hospital, Taichung, Taiwan

${ }^{12}$ Institute of Medicine, Chung Shan Medical University, Taichung, Taiwan

${ }^{13}$ Department of Nursing, College of Health, National Taichung University of Science and Technology, Taichung, Taiwan

${ }^{14}$ Department of Emergency Medicine, Taipei Veterans General Hospital,

Taoyuan Branch, Taoyuan, Taiwan

${ }^{15}$ Institute of Occupational Medicine and Industrial Hygiene, National Taiwan

University College of Public Health, Taipei, Taiwan

Contributors L-HC and M-TT made substantial contributions to the concept and design of the study. J-HC, C-KH and VC-RH carried out data analysis and interpretation. L-HC and M-SH wrote manuscript. L-YL, S-YH and M-SH involved in final approval and critical revision.

Funding This study was supported in part by Taiwan's Ministry of Health and Welfare Clinical Trial and Research Center of Excellence (MOHW105-TDU-B-212-133019), China Medical University Hospital; Academia Sinica Taiwan Biobank; Stroke Biosignature Project (BM10501010037); NRPB Stroke Clinical Trial Consortium (MOST 104-2325-B-039-005); Tseng-Lien Lin Foundation, Taichung, Taiwan; Taiwan Brain Disease Foundation, Taipei, Taiwan; and Katsuzo and Kiyo Aoshima Memorial Funds, Japan. This study was also partly supported by research grants V104C-085, V105C-131 and V104E11-004-MY2 to L-YL from Taipei Veterans General Hospital, Taipei, Taiwan, and by research grant of MOST 103-2314-B-075-005-MY2 to LYL from Taiwan's Ministry of Science and Technology.

Competing interests None declared.

Provenance and peer review Not commissioned; externally peer reviewed.

Data sharing statement No additional data are available.

Open Access This is an Open Access article distributed in accordance with the Creative Commons Attribution Non Commercial (CC BY-NC 4.0) license, which permits others to distribute, remix, adapt, build upon this work noncommercially, and license their derivative works on different terms, provided the original work is properly cited and the use is non-commercial. See: http:// creativecommons.org/licenses/by-nc/4.0/

\section{REFERENCES}

1. Whiting DR, Guariguata L, Weil C, et al. IDF diabetes atlas: global estimates of the prevalence of diabetes for 2011 and 2030. Diabetes Res Clin Pract 2011;94:311-21.

2. Guariguata L. By the numbers: new estimates from the IDF Diabetes Atlas Update for 2012. Diabetes Res Clin Pract 2012;98:524-5.

3. Kitabchi AE, Umpierrez GE, Fisher JN, et al. Thirty years of personal experience in hyperglycemic crises: diabetic ketoacidosis and hyperglycemic hyperosmolar state. J Clin Endocrinol Metab 2008;93:1541-52.

4. Kitabchi AE, Umpierrez GE, Miles JM, et al. Hyperglycemic crises in adult patients with diabetes. Diabetes Care 2009;32:1335-43.
5. Nyenwe EA, Kitabchi AE. Evidence-based management of hyperglycemic emergencies in diabetes mellitus. Diabetes Res Clin Pract 2011;94:340-51.

6. Lorber D. Nonketotic hypertonicity in diabetes mellitus. Med Clin North Am 1995;79:39-52.

7. Kitabchi AE, Umpierrez GE, Murphy MB, et al. Management of hyperglycemic crises in patients with diabetes. Diabetes Care 2001;24:131-53

8. Malone ML, Gennis V, Goodwin JS. Characteristics of diabetic ketoacidosis in older versus younger adults. J Am Geriatr Soc 1992;40:1100-4.

9. Kao Y, Hsu CC, Weng SF, et al. Subsequent mortality after hyperglycemic crisis episode in the non-elderly: a national population-based cohort study. Endocrine 2016;51:72-82.

10. Wu LS, Chang SH, Chang GJ, et al. A comparison between angiotensin converting enzyme inhibitors and angiotensin receptor blockers on end stage renal disease and major adverse cardiovascular events in diabetic patients: a population-based dynamic cohort study in Taiwan. Cardiovasc Diabetol 2016;15:56.

11. Tsai ML, Mao CT, Chen DY, et al. Short- and long-term major cardiovascular adverse events in carotid artery interventions: a nationwide population-based cohort study in Taiwan. PLOS ONE 2015;10:e0121016.

12. Chou SH, Tung YC, Lin YS, et al. Major adverse cardiovascular events in treated periodontitis: a population-based follow-up study from Taiwan. PLOS ONE 2015;10:e0130807.

13. Wang YF, Chuang MH, Chuang TL, et al. CHADS 2 scores in the prediction of major adverse cardiovascular events in patients with Cushing's syndrome. Int J Endocrinol 2014;2014:138653.

14. Krinsley JS. Association between hyperglycemia and increased hospital mortality in a heterogeneous population of critically ill patients. Mayo Clin Proc 2003;78:1471-8.

15. Umpierrez GE, Isaacs SD, Bazargan N, et al. Hyperglycemia: an independent marker of in-hospital mortality in patients with undiagnosed diabetes. J Clin Endocrinol Metab 2002;87:978-82.

16. Stentz FB, Umpierrez GE, Cuervo R, et al. Proinflammatory cytokines, markers of cardiovascular risks, oxidative stress, and lipid peroxidation in patients with hyperglycemic crises. Diabetes 2004;53:2079-86.

17. Kaiser N, Sasson S, Feener EP, et al. Differential regulation of glucose transport and transporters by glucose in vascular endothelial and smooth muscle cells. Diabetes 1993;42:80-9.

18. Heilig CW, Concepcion LA, Riser BL, et al. Overexpression of glucose transporters in rat mesangial cells cultured in a normal glucose milieu mimics the diabetic phenotype. $J$ Clin Invest 1995;96:1802-14.

19. Razavi Nematollahi L, Kitabchi AE, Stentz FB, et al. Proinflammatory cytokines in response to insulin-induced hypoglycemic stress in healthy subjects. Metab Clin Exp 2009;58:443-8.

20. Zoungas S, Patel A, Chalmers J, et al. Severe hypoglycemia and risks of vascular events and death. $N$ Engl $J$ Med 2010;363:1410-18.

21. Duckworth W, Abraira C, Moritz T, et al. Glucose control and vascular complications in veterans with type 2 diabetes. N Engl J Med 2009;360:129-39.

22. Tancredi M, Rosengren A, Svensson AM, et al. Excess mortality among persons with type 2 diabetes. N Engl J Med 2015;373:1720-32.

23. Lind M, Garcia-Rodriguez LA, Booth GL, et al. Mortality trends in patients with and without diabetes in Ontario, Canada and the UK from 1996 to 2009: a population-based study. Diabetologia 2013;56:2601-8.

24. Bihan $\mathrm{H}$, Backholer K, Peeters A, et al. Socioeconomic position and premature mortality in the AusDiab Cohort of Australian adults. Am J Public Health 2016;106:470-7.

25. Ribeiro AL, Duncan BB, Brant LC, et al. Cardiovascular health in Brazil: trends and perspectives. Circulation 2016;133:422-33. 
Correction: Association between hyperglycaemic crisis and long-term major adverse cardiovascular events: a nationwide population-based, propensity score-matched, cohort study

Chang L-H, Lin L-Y, Tsai M-T, et al. Association between hyperglycaemic crisis and longterm major adverse cardiovascular events: a nationwide population-based, propensity score-matched, cohort study. BMJ Open 2016;6:e012233. Dr Sung-Yuan Hu is cocorresponding author of this paper. Following 'Correspondence to Dr Ming-Shun Hsieh; simpleabei@yahoo.com.tw' on the first page of this paper, 'Co-correspondence to Dr Sung-Yuan Hu; song9168@pie.com.tw’ should have been included.

Open Access This is an Open Access article distributed in accordance with the Creative Commons Attribution Non Commercial (CC BY-NC 4.0) license, which permits others to distribute, remix, adapt, build upon this work noncommercially, and license their derivative works on different terms, provided the original work is properly cited and the use is non-commercial. See: http://creativecommons.org/licenses/by-nc/4.0/

BMJ Open 2016;6:e012233corr1. doi:10.1136/bmjopen-2016-012233corr1 